FACULDADE DE CIÊ NCIAS ECONÔ MICAS DA UFRGS

REESTRUTURAÇÁ O DA PRODUÇÁ O AGRICOLA NO RIO GRANDE DO SUL, DE 1970 A 1996 E UMA ESTIMAÇȦ O PARA 2012 TIAGO WICKSTROM ALVES

A CRIMINALIDADE NA RECIAO METROPOLTANA DE SALVADOR JOSÉ CARRERA FERNANDEZ, LUIZ FERNANDO LOBO

COMPEIITIVIDADE INTERNACIONAL EM SOFTWARE: UM ESTUDO SOBRE A EXPERIÊNCIA DE FLORIANÓ POLIS HOVÉDO NUNES LINS

MODELOS DE ORGANIZAÇẢ O E REPARTIÇẢ O DE RENDAS NA CADEIA PRODUTIVA DO GÁS NATURAL.

HELder QUEIROZ PINTO Jú NIOR, RODOLFO TORRES dOS SANTOS

REGIMES MONETÁ RIOS E DIVIDA PÚ BLICA: UMA ANÁ LISE DE MECANISMOS ALTERNATIVOS DE COORDENAÇÃO MACROECONÓ MICA

manoel Carlos de Castro Pires

ECONOMIA DOS RECURSOS NATURAIS E SEUS INDICADORES DE ESCASSEZ: UMA QUESTÃ O DE SUSTENTABILIDADE ANDREA SALES SOARES DE AZEVEDO MELO

O ECOPROTECIONISMO AGRICOLA NA UNIĀ O EUROPEIA E SEUS POSSIVEIS IMPACTOS SOBRE A ECONOMIA BRASILEIRA Rodrigo daniel Feix, Clá udio R. Fóffano Vasconcelos

PADRÓ ES DE DESENVOLVIMENTO, FUNÇ Ó ES ESTATAIS E ENDIVIDAMENTO NO CAPITALISMO CONTEMPORÁNEO paulo Balanco, Eduardo Costa Pinto

A INTERNACIONALIZAÇÃO DO VAREJO A PARTIR DOS CASOS WAL-MART E CARREFOUR

Armando joảo dalla Costa

UMA ANÁ LISE ECONOMÉTRICA DO FUTEBOL BRASILEIRO ARI Francisco de Araujo JR, Clá udio D. SHIKIDA, LEONARDO M. MONASTERIO

O BRASIL E A ECONOMIA INTERNACIONAL: RECUPERAÇÃ O E DEFESA DA AUTONOMIA NACIONAL

RESENHA DE ALEXANDRE CÉ SAR CUNHA LEITE

REGIMES MONETÁ RIOS: TEORIA E A EXPERIÊNCIA DO REAL ResenHa de Fernando Ferrari Filho

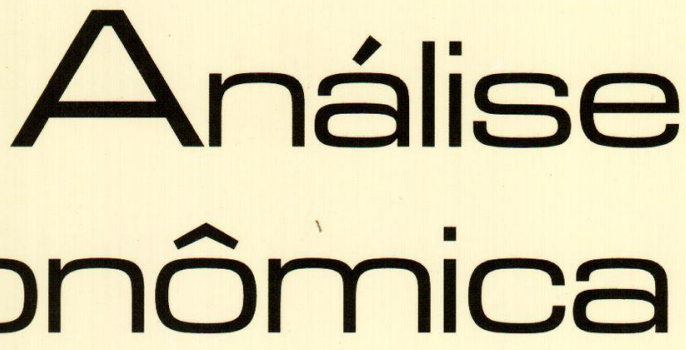


Universidade Federai. do Rio Grande do Sul Reitor: Prof José Carlos Ferraz Hemnemann

Facul dade de Cuéncias Economicas

Diretor: Prof. Gentil Corazza

Ceniro de Estudos f Prequisas Economicas

Diretor: Prof. Lovois de Andrade Miguel

Depariamenio de Crências Economicas

Chefe: Prof Ricardo Dathein

Departamento de Cîncias Coniábeis f A tuaria Chefe: Prof. Ceno Odilo Kops

Curso de Pós-Graduaçó em Economia

Coordenador: Prof. Fernando Ferrari Filho

Curso de Pos-Grainaça em Desenvolvimento RuRAI

Coordenador: Prof. Paulo Dabdab Waquil

Conseluo Eni tokial: André Moreira Cunha (UFRGS) Carlos G. A. Mielitz Netto (UFRGS), Carlos Henrique Hom (UFRGS). Eduardo A. Maldonado Filho (UFRGS). Eleutério F S. Prado (USP), Eugênio Lagemann (UFRGS), Fernando Cardim de Carvalho (UFRJ). Femando Ferrari Filho (UFRGS), Fernando de Holanda Barbosa (FGV/RJ), Flávio Augusto Ziegelmann (UFRGS), Flávio Vasconcellos Comin (UFRGS), Gentil Corazza (UFRGS), Giácomo Balbinot to Neto (UFRGS), Gustavo Franco (PUC/RJ) Hélio Henkin (UFRGS), Jan A. Kregel (UNCTAD), João Rogério Sanson (UFSC), Joaquim Pinto de Andrade (UnB), Júlio César Oliveira (UFRGS), Luiz Estrella Faria (UFRGS), Luiz Paulo Ferreira Nogueról (UFRGS), Marcelo S Portugal (UFRGS), Maria Alice Lahorgue (UFRGS), Octávio Augusto Camargo Conceicão (UFRGS), Paul Davidson (University of Tennessee), Paulo D. Waquil (UFRGS), Pedro C. D. Fonseca (UFRGS), Philip Arestis (University of Cambridge), Ricardo Dathein (UFRGS) Ronald Otto Hillbrecht (UFRGS), Sabino da Silva Porto Jr (UFRGS), Sérgio M. M. Monteiro (UFRGS), Stefano Florissi (UFRGS) e Werner Baer (University of IIIinois at Urbana - Champaign)

Comissão Emroniai: Eduardo Augusto Maldonado Filho, Fernando Ferrari Filho, Hélio Henkin. Marcelo Savino Portugal, Paulo Dabdab Waquil e Sérgio Marley Modesto Monteiro.

EnIrok: Sérgio Marley Modesto Monteiro

Ediror Adjun ro: Hélio Henkin

Secretário: Emerson Douglas Neves

REVISÃo DE IEX ros: Vanete Ricacheski

Emioração: Núcleo de Editoração e Criação da

Gráfica da UFRGS - Janaína Horn e Junia Saedt

Fundador: Prof Antonio Carlos Santos Rosa
Os materiais publicados na revista Análise Econômica são da exclusiva responsabilidade dos autores. É permitida a reprodução total ou parcial dos trabalhos, desde que seja citada a fonte. Aceita-se permuta com revistas congêneres. Aceitam-se, também, livros para divulgacão, elaboraça de resenhas e recensões Toda correspondência: material para publicação (vide normas na terceira capa), assinaturas e permutas devem ser dirigidos ao seguinte destinatário:

Prof. Sérgio Marley Modesto Monteiro Revista Andilse Económica - Av. João Pessoa, 52 CEP 90040-000 PORTO ALEGRE - RS, BRASIL Telefones: (051) $33163513 / 33164164$

Fax: (051) 33163990 - E-mail: rae@vortex ufrgs.br

A Revista Análise Econômica agradece a colaboração dos pareceristas do número 43, abaixo relacionados:

Adalmir Antonio Marquetti

André Moreira Cunha

Carlos José Caetano Bacha

Carlos Mielitz. Netto

Clailton Ataídes de Freitas

Claudio Roberto Fóffano Vasconcelos

Eduardo Ernesto Filippi

Eduardo Pontual Ribeiro

Eleuterio Fernando da Silva Prado

Fernando J Cardim de Carvalho

Fernando Augusto Mansor de Mattos

Fernando Ferrari Filho

Flávio Tosi Feijó

Flavio Vilela Vieira

Francisco Paulo Cipolla

Gentil Corazza

Gíacomo Balbinotto Neto

Helio Henkin

Jefferson Andronio Ramundo Staduto

João de Deus Sicsú Siqueira

José Carrera Fernandes

Leonardo Monteiro Monasterio

Luís Fernando de Paula

Luis Roberto Nascimento

Manoel Carlos de Castro Pires

Octavio Augusto Camargo Conceição

Patrízia Raggi Abdallah

Robson Antonio Grassi

Ronald Otto Hilbrech

Tiago Wickstrom Alves

Tito Belchior Silva Moreira

Análise Econônica

Ano 23, n ${ }^{\circ} 44$, setembro, 2005 - Porto Alegre

Faculdade de Ciências Economicas, UFRGS, 2000

Periodicidade semestral, março e setembro

1. Teoria Econômica - Desenvolvimento Regional -

Economia Agrícola - Pesquisa Teórica e Aplicada -

Periódicos. I.. Brasil

Faculdade de Ciências Econômicas,

Universidade Federal do Rio Grande do SuI

CDD 330.05

CDU $33(81)(05)$ 


\title{
O Brasil e a Economia Internacional: recuperação e defesa da autonomia nacional
}

\author{
Paulo Nogueira Batista Jr. \\ Alexandre César Cunha Leite ${ }^{I^{*}}$
}

\section{Resenha}

O professor Paulo Nogueira Batista Jr. é um pensador autônomo, no melhor sentido da palavra. Segundo o Houaiss, entende-se por autônomo aquele que é dotado da faculdade. de determinar por si próprio, sem a interferência ou imposição de outrem, normas, métodos e técnicas e, no caso específico da economia, análises conjunturais.

Em seu último livro, O Brasil e a Economia Internacional, o professor demonstra novamente esta sua autonomia. Ao contrário do que argumenta a grande maioria dos pensadores atuais, o professor Paulo Nogueira Batista Jr. afirma na apresentação do seu livro que a economia brasileira vem apresentando melhoria modesta quanto à sua evolução.

Seu livro está dividido em duas partes. A primeira parte trata, com propriedade, a interação entre a economia brasileira e as finanças internacionais. $O$ ponto relevante de tal análise é que o texto ultrapassa as duas visões antagônicas existentes. Quando discute a globalização, seu texto não é cético, no sentido pessimista e irreversível, conotação usada em demasia pelos teóricos desta vertente. Ao mesmo tempo, seu texto não é eufórico e emotivo, aceitando indiscriminadamente a ocorrência do fenômeno em questão.

Essa primeira parte encontra-se organizada cronologicamente. O primeiro texto trata do contexto econômico globalizado e das suas repercussões em economias emergentes como a brasileira e a argentina. Nesse primeiro texto devem ser frisados dois pontos: (1) a presença da idéia de assimetria da globalização, principalmente no que tange às diferenças entre os mercados de trabalho e de capital; e (2)

* Mestre em Economia Política pela Pontificia Universidade Católica de São Paulo - PUC-SP (ANPEC). 
a discussão referente aos regimes monetários adotados frente ao fenômeno da globalização, desnudando a fragilidade de tais regimes.

O segundo texto discute o contexto do Plano Real frente à vulnerabilidade externa. Esta vulnerabilidade é pelo autor entendida como uma junção do elevado déficit em conta corrente, a inadequação do controle dos fluxos de capitais e a insuficiência das reservas internacionais. Essa vulnerabilidade é tida como herança da política econômica implementada no Plano Real. Não se deve determiná-la como herança maldita, como vem sendo veiculado nos meios acadêmicos e midiáticos, mas acredita-se que existe um caráter limitador do bom funcionamento da economia, decorrente da armadilha construída pela valorização da moeda nacional somada à elevação dos juros nominais. O ponto relevante é a preocupação com o desenvolvimento econômico, diga-se de passagem, o próprio título do livro não nos deixa dúvida quanto à importância concedida pelo autor a esse tema. Quanto a esse quesito, a preocupação recai sobre o processo de inserção internacional, enfatizandose o controle sobre os fluxos de capital estrangeiro. Este tema será retomado no terceiro texto da primeira parte do livro. Devido a limitação de espaço, destaca-se a ênfase na preocupação com o desenvolvimento econômico. Para o autor, a retomada demanda um ataque em várias frentes. Mas seguindo uma coerência com o que vem sendo escrito, o autor elenca, entre vários aspectos, a definição de uma política cambial ativa e autônoma; uma contribuição decisiva do Banco Central; e a superação da vulnerabilidade, que será fundamental para o retorno do dinamismo da economia brasileira.

A segunda parte é composta por dois textos. O primeiro texto debate a controversa Área de Livre Comércio das Américas. Este debate é feito através de uma descrição do andamento das negociações, tendo como limite temporal o ano de 2002. Vale ressaltar desse texto as seguintes conclusões: (1) a importância atribuída a esta proposta pelos centros decisórios da economia hegemônica, no sentido da palavra proposto por Arrighi. Nas palavras do autor, "em países como o Brasil, propostas problemáticas, às vezes claramente nocivas, mas que atendem aos interesses das forças hegemônicas no plano internacional, logo adquirem o status de inevitáveis ou inexoráveis"; (2) as condições da economia brasileira sinalizam claramente que não há condições para se enfrentar tamanho desafio; e por fim, mas não menos importante, (3) a desmistificação da idéia de que o país seria jogado no isolamento e no ostracismo se não se juntasse ao Bloco. Cabe uma observação ao leitor, por falta de espa- 
ço, não foi feita referência ao tópico 5 deste capítulo, mas este merece atenção do leitor que visa compreender as propostas da economia hegemônica para os integrantes do Bloco.

O capítulo 5 faz uma apresentação das negociações nas quais o Brasil encontra-se envolvido. Seguindo a ordem cronológica dos fatos, percorre os anos de 2003 e 2004, ou seja, os dois primeiros anos do governo Lula. Merece destaque a posição contrária do então presidente quando sua posição política situava-se na oposição. Este, agora na posição do governo, iniciou seu governo questionando aspectos essenciais da ALCA, principalmente aqueles que davam caráter desequilibrado nas negociações. Talvez, representando uma reação às negativas norte-americanas, o Brasil estreitou seus laços comerciais com a União Européia. Contudo, vale observar que ambas as negociações apresentam choques nas negociações, devido, essencialmente, à busca de ganhos dos centros em detrimento das economias em desenvolvimento.

Por fim, com o intuito informativo, deve ser dito que o capitulo 4 do livro, segundo informaçōes do próprio autor, é uma versão modificada de um artigo publicado na Estudos Avançados da USP. Porém, em nada minimiza o valor da publicação do Professor Paulo Nogueira Batista Jr. Muito pelo contrário, trata-se de leitura obrigatória, abusando de um chavão editorial, mas sem nenhuma pretensão, para quem deseja tomar contato com uma forma de enxergar os fatos relacionados à economia internacional e sua intima relação com a economia brasileira, sem um vinculo específico a nenhuma corrente interpretativa. Como o próprio autor se intitula, é um trabalho de um nacionalista, individualista, intransigente, mas de qualidade inquestionável.

\section{Referência bibliográfica}

BATISTA Jr, Paulo Nogueira. O Brasil e A Economia Intermacional: recuperação e defesa da autonomia nacional. Rio de Janeiro: Elsevier, 2005. 175 p. 